\title{
MATHEMATICAL STUDY OF TRANSPORT PHENOMENA ALONG A TUYERE OF THE TENIENTE CONVERTER
}

\author{
J. SAN MARTÍN, R. GORMAZ, C. CONCA, F.-Z. SAOURI, A. BENADDI, \\ R. FUENTES, AND P. RUZ
}

Received 14 March 2005; Revised 29 July 2005; Accepted 24 August 2005

This paper presents a comprehensive mathematical model of transport phenomena which occur along a tuyere of the Teniente converter during injection of oxygen-enriched air. Inlet pressure, gas velocity and temperature, the dimensions of the tuyere, and the properties of gas are the basic data. From these inputs, temperature distribution of the refractory walls of the converter around the tuyere as well as the velocity, pressure, and the Mach number along the pipe can be calculated. In this model, the heat transfer through the metal jacket of the tuyere and the refractory lining are duly taken into account. More precisely, a mathematical model is developed where the equations of momentum and energy of the gas are coupled with the equations of heat transfer inside the solid part. This new model couples a partial differential equation in the solid part with four ordinary differential equations in the gas flow.

Copyright (c) 2006 J. San Martín et al. This is an open access article distributed under the Creative Commons Attribution License, which permits unrestricted use, distribution, and reproduction in any medium, provided the original work is properly cited.

\section{Introduction}

In Chile, one stage of copper refining is completed in a special cylindrical converter: the Teniente converter (CT) furnace which is intended to eliminate the most oxidizable metallic elements present in the mineral concentrate. In this stage, oxygen-enriched air is injected into the smelting bath through an array of tuyeres to feed the chemical reactions which separate out the impurities contained in the copper.

Our objective is to carry out a mathematical modeling and numerical experiments of the air flow that is injected through the tuyeres and its influence on the temperature of the CT walls. The thermal variables are of primary interest here, but because there is a compressible fluid involved, which is injected at high velocities, the thermal variables are coupled with the dynamic ones.

In this work, the interaction between the tuyere and the CT walls will be simplified since interest will be focused on a local analysis of the tuyere and the CT walls.

Hindawi Publishing Corporation

Mathematical Problems in Engineering

Volume 2006, Article ID 23754, Pages 1-12

DOI 10.1155/MPE/2006/23754 
Mathematically, the domain can be divided into two regions. The first corresponds to the gas that circulates in the interior of the tuyere, or the "fluid region." The second corresponds to the metallic jacket of the tuyere and the refractory lining as well as the metallic external shell, this is the "solid region."

Krivsky and Schuhmann [3] calculated the distribution of temperatures around a tuyere. These authors suppose the temperature of the gas in the tuyere to be known, and using a relaxation method they found the distribution of temperatures in the refractory lining. One of our goals in this paper is to carry out an exhaustive study of the flow in the tuyere including heat transfer effects. The model in the fluid region is based on Hugoniot's equations, which assume that the gas is compressible, ideal, and has onedimensional motion along the tuyere. The full model is obtained by coupling Hugoniot's equations with the heat transfer equation through the metal jacket of the tuyere and the surrounding converter walls. The interaction of both equations appears in the heat flow transferred from one zone to another. In mathematical terms, the model presented corresponds to a system of partial differential equations coupled with a system of ordinary differential equations.

The coupled system is solved, numerically, by using an iterative numerical scheme divided into two steps. In the first step, the distribution of temperatures in the solid part of the system is calculated using the finite element method. In this step, it is assumed that the distribution of temperatures of the gas and the heat transfer factor in the jacket of the tuyere are known. In the second step, the distribution of temperatures of the gas in the tuyere is calculated. Here we use the distribution of temperatures already calculated in the previous step.

The paper is presented as follows. In Section 2, we write down the mathematical model first for the solid part, and next, for the gas in the tuyere. In Section 3, we show the numerical results, and in Section 4 we give some conclusions and components on the application of the results to the real operation of the CT.

\section{Modeling of transport phenomena along a tuyere}

This section is divided into three parts. Firstly, we derive a mathematical model for the heat transfer inside the solid part. Secondly, we write down general equations for the dynamics of the gas in the tuyere which are simplified for the one-dimensional case in Section 2.2. Finally, in Section 2.3 both models are coupled.

2.1. The model for the solid part. We denote the solid domain by $\Omega_{s}$ (see Figure 2.1). This domain, that is found around the tuyere, we assume has cylindrical symmetry. Its boundary can be divided into the following parts. $\Gamma_{3}$ borders $\Omega_{s}$ with the interior of the CT, where the liquid copper bath is at a temperature of $1300^{\circ} \mathrm{C} . \Gamma_{4}$ is that part of the CT which is exposed to external air. $\Gamma_{1}$ is the border in the axial direction that defines the dimensions of the domain under study. It is assumed that this part of the boundary is sufficiently far from the axis of the tuyere so that heat transfer is zero. The interface between the solid domain and the gaseous domain is $\Gamma_{2}$. Furthermore, as the tuyere is 


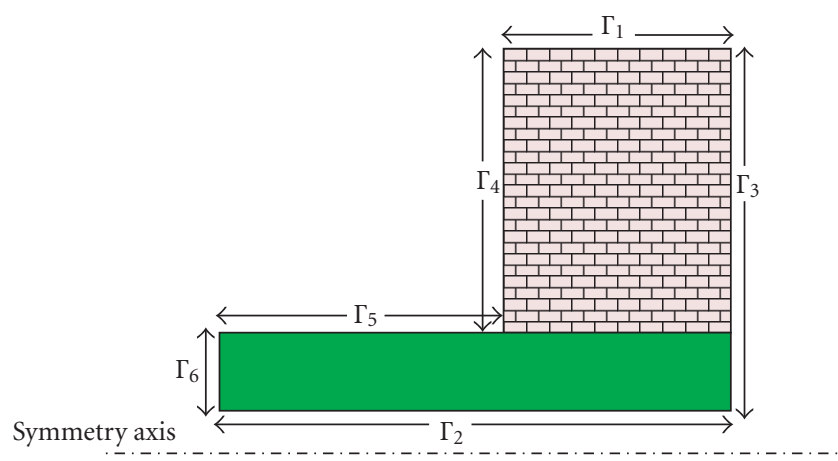

Figure 2.1. Effective domain of calculation.

larger than the walls of the CT, we consider the two additional borders $\Gamma_{5}$ and $\Gamma_{6}$, as illustrated in Figure 2.1.

We will write the equations of heat propagation in the domain $\Omega_{s}$ assuming that the regime is stationary. The equation used in this zone is the classical heat equation

$$
-\operatorname{div}\left(\kappa_{s} \operatorname{grad} T\right)=0 \quad \text { in } \Omega_{s},
$$

where $T$ is the temperature in the solid domain. Here, the coefficient of conductivity in the solid part, denoted by $\kappa_{s}$, takes different values in the metal jacket of the tuyere more than in the refractory brick lining.

The boundary conditions for (2.1) are the following:

$$
\begin{aligned}
& \kappa_{s} \frac{\partial T}{\partial n}=0 \quad \text { on } \Gamma_{1} \text {, with } x \in[0, L], \\
& \kappa_{s} \frac{\partial T}{\partial n}=h\left(T-T_{\text {ext }}\right) \quad \text { on } \partial \Omega_{s} \backslash \Gamma_{1},
\end{aligned}
$$

where $h$ is the heat transfer factor for convection between the solid boundary and the external medium. This factor has different values depending on the geometry and the external fluid in contact with the calculation domain. $T_{\text {ext }}$ is the temperature of the external fluid in contact with our calculation domain. This problem can be solved in various ways, given $T_{\text {ext }}$, for example, with the finite elements method which in fact we use here.

2.2. The model for gas in the tuyere. Here we will give the mathematical translation of the conservation laws of mass, momentum, and energy in the flow of air injected through a tuyere. We denote the region occupied by the gas in the tuyere by $\Omega_{f}$, which is bounded by $\Gamma_{2}$, and the parallel surfaces $[x=0.0]$ and $[x=0.9]$. Here the one-dimensional variable $x$ runs along the symmetry axis of the tuyere. 
The three-dimensional equations of conservation of mass, momentum, and energy in $\Omega_{f}$ are, respectively,

$$
\begin{gathered}
\operatorname{div} \rho \vec{v}=0, \\
\rho(\vec{v} \cdot \operatorname{grad}) \vec{v}=\operatorname{div} \sigma+\rho \vec{g}, \\
\rho(\vec{v} \cdot \operatorname{grad}) e=\vec{\sigma}: \vec{D}(\vec{v})-\operatorname{div} \vec{q}+r,
\end{gathered}
$$

where $\rho$ is the gas density, $\vec{v}$ is the velocity field, $\sigma$ is the stress tensor, $\vec{g}$ is the gravity force, $e$ is the density of the gas internal energy, $\vec{q}$ is the heat flow vector in the gas, and $r$ is the external heat source by unit of volume.

If we use the averaged values over a cross section of a tuyere, the above equations can be written in the following unidimensional form:

$$
\begin{gathered}
\frac{d}{d x}\left(\rho(x) \cdot v_{1}(x)\right)=0, \\
\frac{d}{d x}\left(\dot{m} v_{1}(x)+A P(x)\right)=-\chi \tau(x), \\
\frac{d}{d x}\left(\dot{m} e(x)+A v_{1}(x) P(x)+\dot{m} \frac{v_{1}^{2}(x)}{2}+\dot{m} g h(x)\right)=q_{1}^{\prime}(x) A+q_{r}(x) \chi, \\
P(x)=\frac{\mathrm{R}}{\mu(x)} \rho T,
\end{gathered}
$$

where $\dot{m}(x)=A \rho v_{1}$ is the constant flow of mass into the tuyere, $\chi$ is the perimeter of the tuyere, $\tau(x)$ denotes the transversal shear that the walls exert on the gas in the direction $-\vec{e}_{1}, q_{1}$ is the component of the heat flow vector in the direction of the tuyere axis, $q_{r}$ represents the component of the heat flow vector in the radial direction, $\mathrm{R}$ is the universal constant of gases, and $\mu$ is the molar mass of the gas considered.

The previous system can be interpreted as a linear system of four differential equations with variable coefficients. In order to simplify this system, we use the relation $d e / d T=C_{v}$ valid for perfect gases, where $C_{v}$ is the specific heat of the gas at a constant volume (see [2, page 235]). Other relations of perfect gases used to simplify the previous equations are

$$
\begin{gathered}
C_{p}=C_{v}+\frac{\mathrm{R}}{\mu}, \quad \text { specific heat of the gas at a constant pressure, } \\
\qquad k=\frac{C_{p}}{C_{v}} \\
c=\sqrt{\frac{k P}{\rho}}, \quad \text { velocity of sound in the gas, } \\
M_{a}=\frac{v}{c}, \quad \text { Mach number. }
\end{gathered}
$$


Using the above relations, the above system of equations is transformed into

$$
\begin{gathered}
\frac{P^{\prime}}{P}=\frac{-1}{\left(1-M_{a}^{2}\right)}\left((k-1) M_{a}^{2} S_{q}-\left[1+(k-1) M_{a}^{2}\right] S_{\tau}+M_{a}^{2} S_{\mu}\right), \\
\frac{T^{\prime}}{T}=\frac{k-1}{k\left(1-M_{a}^{2}\right)}\left(\left(1-k M_{a}^{2}\right) S_{q}+k M_{a}^{2} S_{\tau}-S_{\mu}\right), \\
\rho(x)=\frac{P(x) \mu(x)}{R T(x)} \\
v(x)=\frac{\dot{m}}{\rho(x) A}
\end{gathered}
$$

where

$$
\begin{gathered}
S_{\tau}=-\frac{\chi \tau(x)}{A P}, \\
S_{q}=\frac{q_{1}^{\prime}(x) A+q_{r}(x) \chi}{A P v}, \\
S_{\mu}=-\frac{\mu^{\prime}(x)}{\mu(x)}
\end{gathered}
$$

are the sources of the right-hand side of the equation, which respectively depend on the friction effort $\tau$, the dissipated heat $q_{r}$ and $q_{1}^{\prime}$, and the variation of molar mass $\mu$. We will refer to (2.7)-(2.10) as Hugoniot's equations. To couple these equations with the solid part, it is necessary to model the heat exchange $q_{r}$ with the walls and the friction effort $\tau$. In the following section, we summarize the main known empirical formulas for these two parameters in the case of flow in a tuyere.

2.3. Modeling the heat transfer between the tuyere and the walls. The coupling between the tuyere and rigid walls of the converter appears in (2.3) and (2.12) due to the heat transfer between the gas of the tuyere and its metal jacket. This heat exchange will be modeled by the following equation:

$$
q=h\left(T_{f}-T_{p}(x)\right)
$$

where $T_{f}$ is the temperature of the gas, $T_{p}$ is the temperature of the wall, and $h$ is the coefficient of heat transfer factor.

The study of the thermal transfer factor in the case of flows in heat pipes has been done in [4]. There it is shown that

$$
h=C_{p} \rho v M_{\mathrm{ar}},
$$

where $C_{p}$ is the gas' specific heat at constant pressure, $\rho$ is its density, $v$ is the average velocity, and $M_{\mathrm{ar}}$ is the so-called Margoulis number. This Margoulis number can be estimated from the relation of Dipprey and Sabersky (see Mills [4]):

$$
M_{\mathrm{ar}}=\frac{f / 8}{0.9+\left(4.8 k_{*}^{0.2} \operatorname{Pr}^{0.44}-7.65\right)},
$$


Transport phenomena along a tuyere

Table 3.1. Parameter values for Example 3.1.

\begin{tabular}{lcc}
\hline Parameter & Symbol & Value \\
\hline Inlet pressure of the tuyere & $P(0)$ & $20 \mathrm{psi}$ \\
Inlet temperature of the tuyere & $T(0)$ & $100^{\circ} \mathrm{C}$ \\
Volume flow in the tuyere & $q=\dot{\mathrm{m}} / \mathrm{A}$ & $0.4526 \mathrm{~m}^{3} / \mathrm{s}$ \\
Heat transfer factor of the boundary $\Gamma_{3}$ & $h_{3}$ & $1000 \mathrm{~W} /\left(\mathrm{m}^{2 \circ} \mathrm{C}\right)$ \\
Heat transfer factor of the boundary $\Gamma_{4}$ & $h_{4}$ & $50 \mathrm{~W} /\left(\mathrm{m}^{2 \circ} \mathrm{C}\right)$ \\
Heat transfer factor of the boundaries $\Gamma_{5}$ and $\Gamma_{6}$ & $h_{5}, h_{6}$ & $50 \mathrm{~W} /\left(\mathrm{m}^{2 \circ} \mathrm{C}\right)$ \\
External temperature at the boundary $\Gamma_{3}$ & $T_{\text {ext, } 3}$ & $1300^{\circ} \mathrm{C}$ \\
External temperature at the boundaries $\Gamma_{4}, \Gamma_{5}$, and $\Gamma_{6}$ & $T_{\text {ext, }, 4}, T_{\text {ext, }, 5}$ & $50^{\circ} \mathrm{C}$ \\
\hline
\end{tabular}

where $f$ is the friction factor of Darcy in the heat pipe (see the following paragraph), $k_{*}=\left(v r_{s} / \nu\right) \sqrt{f / 8}, r_{s}$ is the average rugosity of the pipe wall, $v$ is the cinematic viscosity of the gas, $\operatorname{Pr}=(\nu \rho / \kappa) C_{p}$ is the Prandtl number, and $\kappa$ is the thermal conductivity of the gas.

The study of the friction factor or the resistance $f$ for the case of heat pipes is done in [1]. There the dependence on the pipe's rugosity and on the Reynolds number is shown. The friction factor $f$ can be obtained from the Colebrook-White equation (see [4]):

$$
\frac{1}{\sqrt{f}}=-2 \log \left(0.27 \frac{r_{s}}{D}+\frac{2.51}{\mathrm{R}_{e} \sqrt{f}}\right)
$$

\section{Numerical results}

In this section, we present some numerical results corresponding to the application of the previous model to the study of temperature distribution along the tuyere and in the surrounding walls. As seen in Section 2, this fluid-solid-type interaction leads to a coupled system of equations which includes (2.3) for the solid part, (2.7)-(2.10) for the fluid part, and (2.15) along the fluid-solid interface. When solving (2.2)-(2.3), the distribution of temperatures in the solid part of the system is calculated using standard finite elements. In this step, it is assumed that the distribution of temperatures of the gas and the heat transfer factor in the jacket of the tuyere are known. The resolution of (2.7)-(2.10) yields the distribution of temperatures of the gas in the tuyere. Here the temperatures along the solid jacket of the tuyere is assumed to be known. The resolution of (2.7)-(2.8) requires the prescriptions of two initial or inlet conditions. In our numerical examples, we have used $P(0)=20$ psi (inlet pressure of the tuyere) and $T(0)=100^{\circ} \mathrm{C}$ (inlet temperature of the tuyere) as shown in Table 3.1.

This strategy provides a numerical scheme which we have run using an original C++ program. It is worthwhile remarking that Hugoniot's equations are solved numerically by an order-4 Runge-Kutta scheme, while in the solid part, the resulting finite element linear system is solved by the conjugate gradient method. In Figure 3.1, the mesh used for the calculations is illustrated. It can be seen that in the bottom part (the boundary between the walls and the tuyere), the mesh is finer. This is because the heat transfer here as well as the temperature gradient are expected to be more important. 


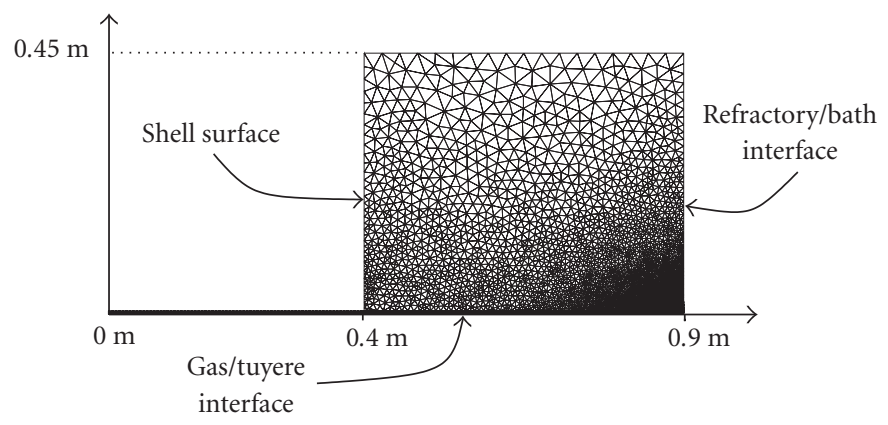

Figure 3.1. The mesh to calculate the solid zone.

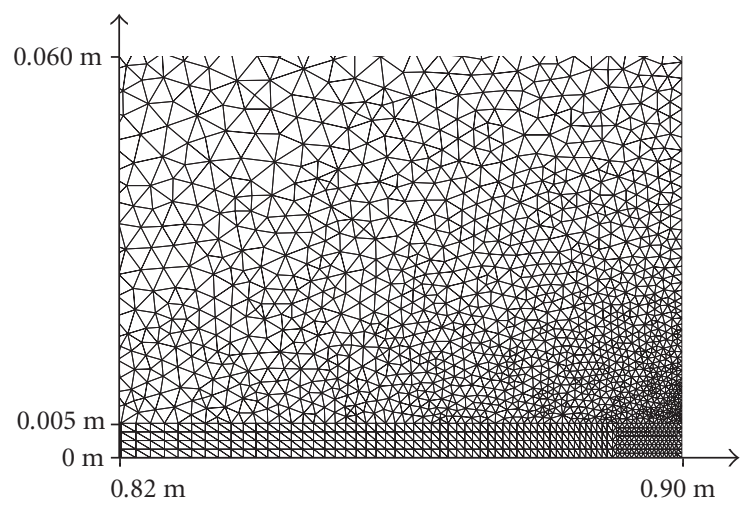

Figure 3.2. Zoom out of the mesh.

For a better view of the refinement, we include a zoom out of the right bottom mesh zone in Figure 3.2.

Example 3.1. In this first calculation, we use the parameters shown in Table 3.1. In Figure 3.3, we show the temperature distribution in the walls of the CT obtained with these parameters of calculation. Finally in Figure 3.4, the heating which the gas suffers by its interaction with the hot walls of the CT is shown.

Example 3.2 (study of the effect of the heat transfer factor in the refractory walls). In this second calculation, we vary the parameters $h_{3}, h_{5}$, and $h_{6}$. These new parameters of calculation are shown in Table 3.2. In Figure 3.5, the temperature distribution in the CT walls obtained with the new parameters of calculation is shown. It should be noted that in this case the exterior temperature of the CT walls is greater than in Example 3.1. Finally, Figure 3.6 shows how the gas is heated by its interaction with the hot walls of the CT. We note that this heating is similar to that of Example 3.1. 


\section{Transport phenomena along a tuyere}

Mini/maxi: (99.709991, 1292.366333)

$1.292 \mathrm{e}+03$
$1.233 \mathrm{e}+03$
$1.173 \mathrm{e}+03$
$1.113 \mathrm{e}+03$
$1.054 \mathrm{e}+03$
$9.942 \mathrm{e}+02$
$9.346 \mathrm{e}+02$
$8.749 \mathrm{e}+02$
$8.153 \mathrm{e}+02$
$7.557 \mathrm{e}+02$
$6.960 \mathrm{e}+02$
$6.364 \mathrm{e}+02$
$5.768 \mathrm{e}+02$
$5.171 \mathrm{e}+02$
$4.575 \mathrm{e}+02$
$3.979 \mathrm{e}+02$
$3.382 \mathrm{e}+02$
$2.786 \mathrm{e}+02$
$2.190 \mathrm{e}+02$
$1.593 \mathrm{e}+02$
$9.971 \mathrm{e}+01$

Figure 3.3. Temperature distribution in the walls of the CT (Example 3.1).

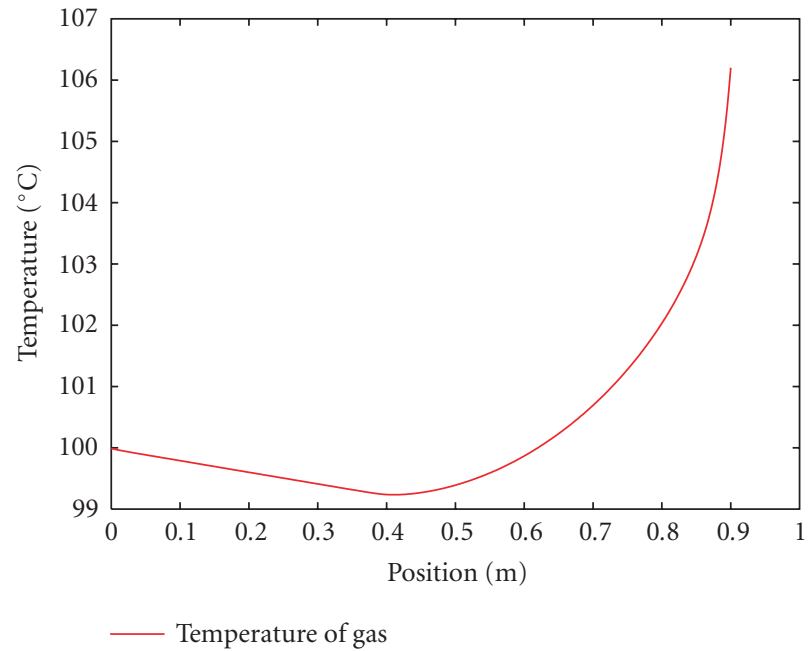

Figure 3.4. Temperature distribution along the tuyere (Example 3.1).

Table 3.2. Parameter values for Example 3.2.

\begin{tabular}{lcc}
\hline Parameter & Symbol & Value \\
\hline Heat transfer factor of the boundary $\Gamma_{3}$ & $h_{3}$ & $500 \mathrm{~W} /\left(\mathrm{m}^{2 \circ} \mathrm{C}\right)$ \\
Heat transfer factor of the boundaries $\Gamma_{5}$ and $\Gamma_{6}$ & $h_{5}, h_{6}$ & $100 \mathrm{~W} /\left(\mathrm{m}^{2 \circ} \mathrm{C}\right)$ \\
\hline
\end{tabular}


Figure 3.5. Temperature distribution in the CT walls (Example 3.2).

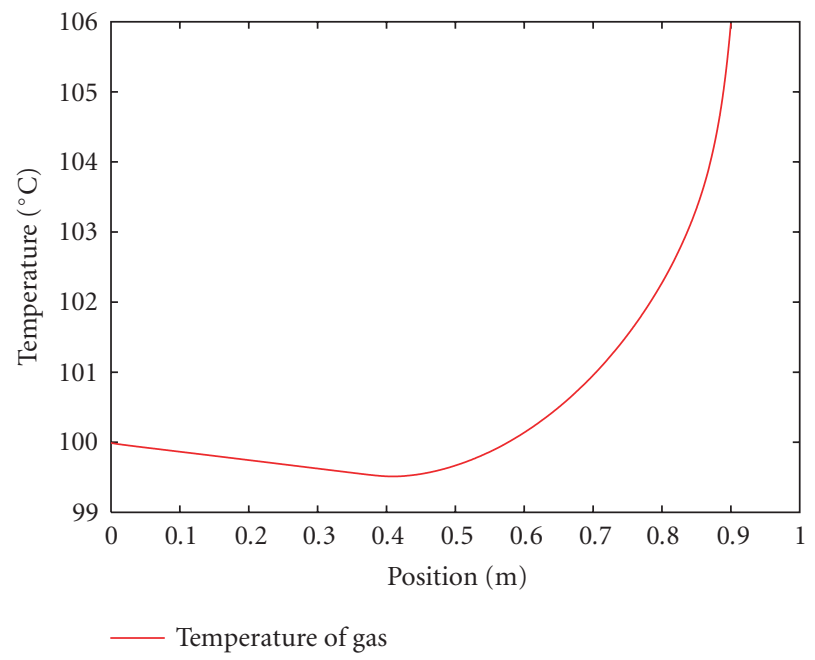

Figure 3.6. Temperature distribution along the tuyere (Example 3.2).

Example 3.3 (study of the effect of flow in the tuyere). Examples 3.1 and 3.2 were run using constant volume flow $\left(q=0.45 \mathrm{~m}^{3} / \mathrm{s}\right)$. The gas heating along the tuyere is just $6^{\circ} \mathrm{C}$ in both examples. We were naturally led to study the influence of the mass flow on the gas heating. Figure 3.7 shows the temperature distribution of gas along the tuyere for different mass flows. Here it can be seen how upon increasing the flow, the heating of the 


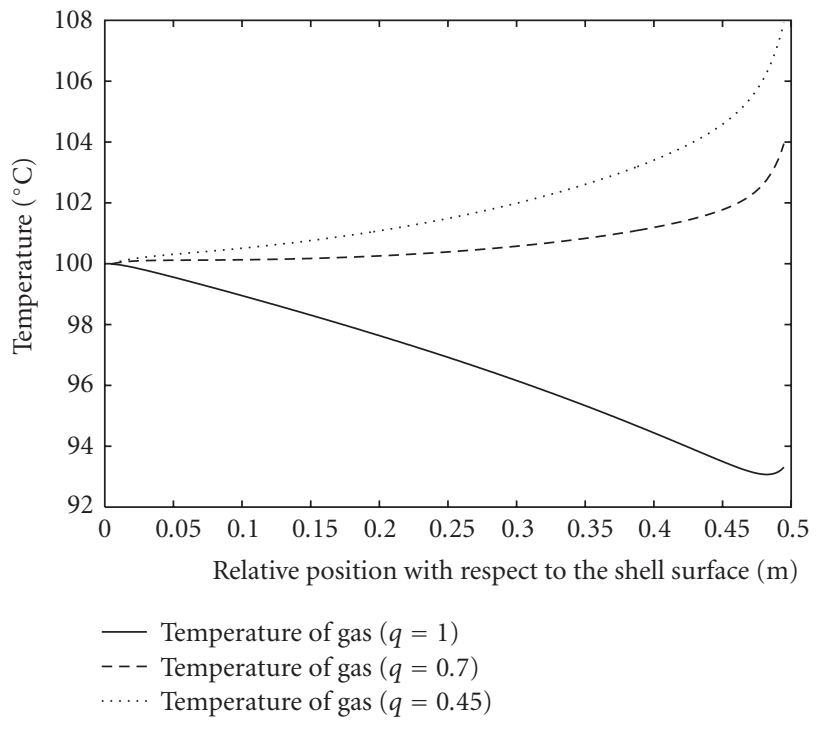

Figure 3.7. Temperatures of the tuyere's gas for different flows.

gas in the tuyere is smaller and even we can see a cooling phenomenon along the tuyere (case 1 in Figure $3.7, q=1 \mathrm{~m}^{3} / \mathrm{s}$ ).

\section{Conclusions}

Different results of heat transfer have been presented. The velocity of compressible gas propagation in the tuyere has been calculated. The numerical calculations show a reheating of the gas at the exit of the pipe along with a cooling of the converter walls near the pipe. In the case of an important flow, a slight cooling of the gas in the pipe is observed.

A mathematical model has been considered for the study of the heat transfer between the walls of the Teniente converter and the oxygen-enriched air injected by the blowing tuyeres. This model allows to calculate the distribution of temperatures in these two domains. In continuation, we determine various parameters such as the velocity, the pressure, and the density inside the tuyere. The presented model allows as well to determine the properties of the flow inside tuyeres and the distribution of temperature in the walls of the CT.

The numerical calculations show an adiabatic cooling of the gas in the part of the tuyere being in the exterior of the converter before the interaction with the walls of the CT and a heating in the zone close to the interior of the CT. This heating, for diverse operation conditions, does not go beyond ten degrees Celsius. There is a critical outlet flow from which a light cooling for the gas in the tuyere is observed. The present calculation allows to see clearly the magnitude and distribution of the cooling of the walls of the converter near the tuyere. 


\section{Nomenclature}

Here are some definitions of parameters used in this paper.

(i) $\dot{q}$ : unitary flow of heat from the wall (thermal energy by unit of time and area).

(ii) $h$ : coefficient of heat transfer.

(iii) $\dot{q}=(1 / \chi)(d \dot{Q} / d x)$ :

(a) $\dot{Q}$ : thermal energy transfer by unit of time,

(b) $\chi$ : perimeter of the pipe,

(c) $d x$ : infinitesimal element of distance through the pipe.

(iv) To calculate $h$, the Margoulis number $M_{\mathrm{ar}}$ is introduced by $M_{\mathrm{ar}} \equiv h / G C_{p}, G=$ $\dot{M} / A$,
(a) $\dot{M}$ : mass flow,
(b) A: transversal area of the pipe,
(c) $C_{p}$ : specific isobaric heat of the flow.

(v) $M_{\mathrm{ar}}$ could be estimated from the relation of Dipprey and Sabersky (see Mills [4]): $M_{\mathrm{ar}}=h / G C_{p}=\left(1 /\left(0.9+\sqrt{f / 8}\left[g^{*}\left(k^{*}, \operatorname{Pr}\right)-7.65\right]\right)\right)(f / 8):$
(a) $g^{*}\left(k^{*}, \operatorname{Pr}\right)=4.8 k^{* 0.2} \operatorname{Pr}^{0.44}$,
(b) $k^{*}=\left(V k_{s} / \nu\right) \sqrt{f / 8}$,
(c) $f$ : Darcy's transversal shear factor,
(d) Pr: Prandtl's number.

(vi) $\operatorname{Pr}=\nu / \alpha$.

(vii) $V$ : average velocity in the pipe section.

(viii) $V=G / \rho$ :
(a) $\rho$ : density of the fluid,
(b) $v$ : cinematic viscosity,
(c) $\alpha$ : thermal diffusivity.

(ix) $\alpha=\kappa / \rho C_{p}$ :
(a) $\kappa$ : thermal conductivity of the fluid (Fourier's law),
(b) $\kappa_{s}$ : thermal conductivity of the solid,
(c) $k_{s}$ : absolute roughness of the wall of the tuyere.

(x) $\operatorname{Re}=V D \rho / \mu$ (Reynolds number):
(a) $\rho$ : density of the fluid,
(b) $\mu$ : dynamic viscosity of the fluid,
(c) $D$ : diameter of the tuyere.

\section{Acknowledgments}

This work has been partially supported by FONDEF through Grant D00I-1068. The first two authors gratefully acknowledge financial support from FONDECYT 1050332 and 1040918. The first and third authors thank the Chilean and French governments through the Scientific Committee ECOS-CONICYT. The authors are endebted to the anonymous referee for careful reading and criticism of an earlier version of the paper. 


\section{Transport phenomena along a tuyere}

\section{References}

[1] F. J. Domínguez, Hidraúlica, 4th ed., Editorial Universitaria, Santiago de Chile, 1974.

[2] G. Duvaut, Mécanique des Milieux Continus, Masson, Paris, 1990.

[3] W. A. Krivsky and J. R. Schuhmann, Heat flow and temperature distribution around a copper converter tuyere, Transactions of the Metallurgical Society of AIME 215 (1959), 82-86.

[4] A. F. Mills, Transferencia de Calor, Irwin, Madrid, 1994.

J. San Martín: Departamento de Ingeniería Matemática and Centro de Modelamiento Matemático, UMR 2071 CNRS-UChile, Facultad de Ciencias Físicas y Matemáticas, Universidad de Chile, Casilla 170/3, Santiago, Chile

E-mail address: jorge@dim.uchile.cl

R. Gormaz: Departamento de Ingeniería Matemática and Centro de Modelamiento Matemático, UMR 2071 CNRS-UChile, Facultad de Ciencias Físicas y Matemáticas, Universidad de Chile, Casilla 170/3, Santiago, Chile

E-mail address: rgormaz@dim.uchile.cl

C. Conca: Departamento de Ingeniería Matemática and Centro de Modelamiento Matemático,, UMR 2071 CNRS-UChile, Facultad de Ciencias Físicas y Matemáticas, Universidad de Chile, Casilla 170/3, Santiago, Chile

E-mail address: cconca@dim.uchile.cl

F.-Z. Saouri: Departamento de Ingeniería Matemática and Centro de Modelamiento Matemático, UMR 2071 CNRS-UChile, Facultad de Ciencias Físicas y Matemáticas, Universidad de Chile, Casilla 170/3, Santiago, Chile

E-mail address: fsaouri@dim.uchile.cl

A. Benaddi: Departamento de Ingeniería Matemática and Centro de Modelamiento Matemático, UMR 2071 CNRS-UChile, Facultad de Ciencias Físicas y Matemáticas, Universidad de Chile, Casilla 170/3, Santiago, Chile

E-mail address: benaddi@dim.uchile.cl

R. Fuentes: Instituto de Innovación en Minería y Metalurgia SA, Avenida del Valle 738, Ciudad Empresarial, Huechuraba, Chile

E-mail address: rfuen004@im2.codelco.cl

P. Ruz: Instituto de Innovación en Minería y Metalurgia SA, Avenida del Valle 738, Ciudad Empresarial, Huechuraba, Chile

E-mail address: 1ruz@im2.codelco.cl 


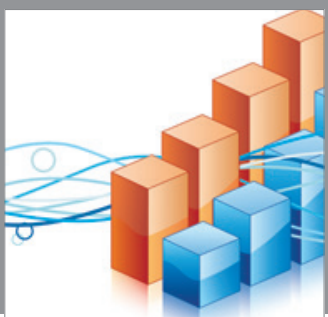

Advances in

Operations Research

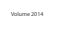

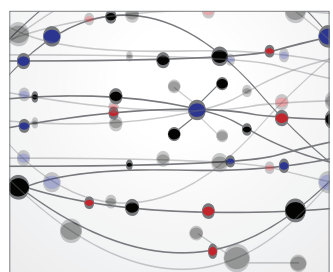

\section{The Scientific} World Journal
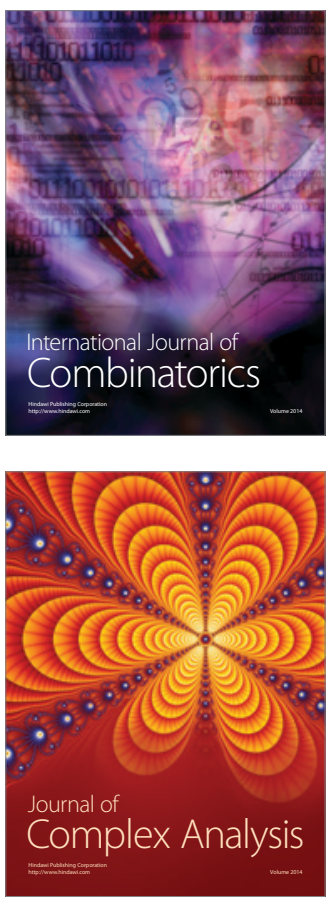

International Journal of

Mathematics and

Mathematical

Sciences
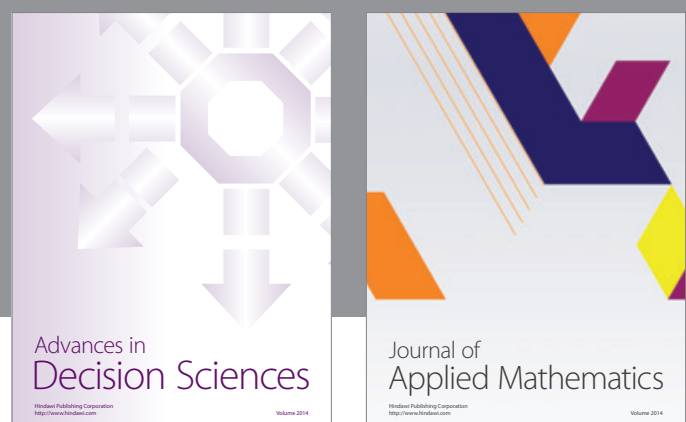

Journal of

Applied Mathematics
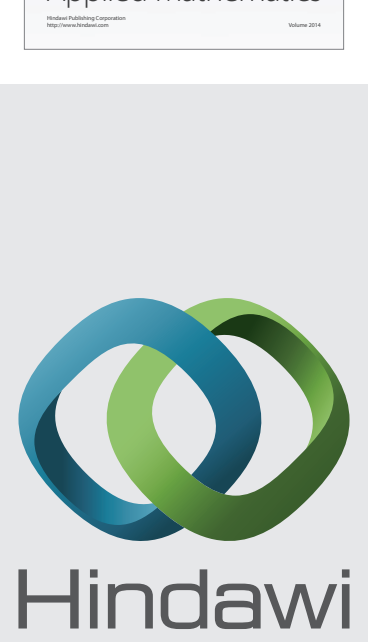

Submit your manuscripts at http://www.hindawi.com
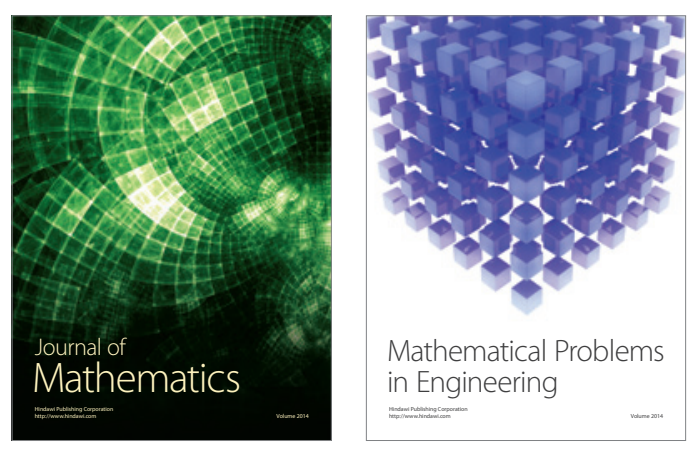

Mathematical Problems in Engineering
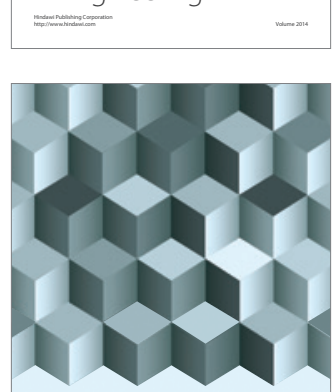

Journal of

Function Spaces
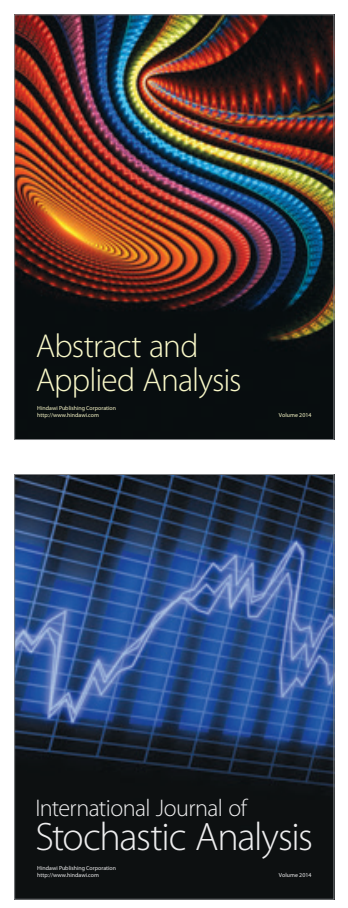

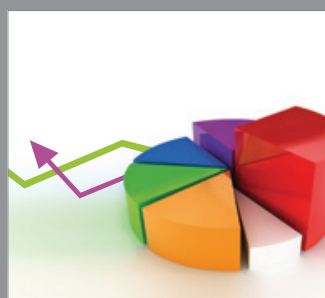

ournal of

Probability and Statistics

Promensencen
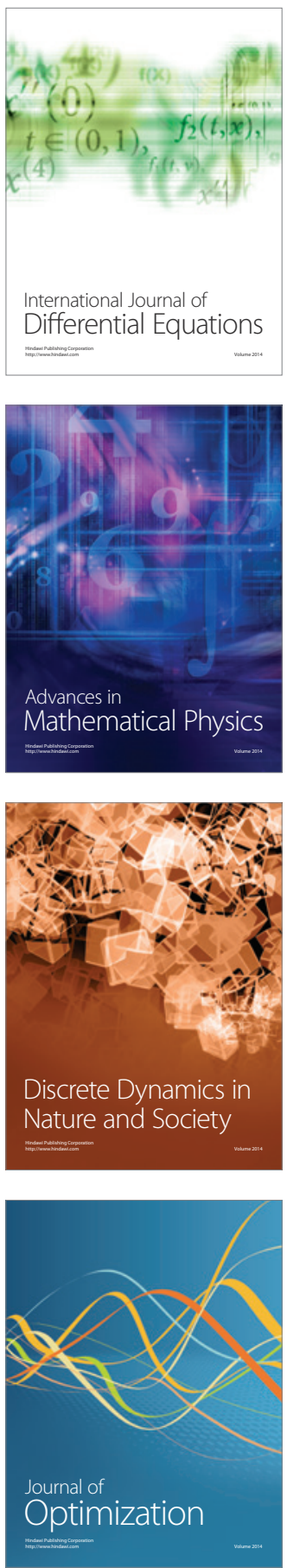